\title{
The design and efficiency of loyalty rewards
}

\author{
Ramon Caminal* \\ Institut d'Anàlisi Econòmica, CSIC, and CEPR
}

October 20, 2009

\begin{abstract}
The goal of this paper is to reexamine the optimal design and efficiency of loyalty rewards in markets for final consumption goods. While the literature has emphasized the role of loyalty rewards as endogenous switching costs (which distort the efficient allocation of consumers), in this paper 1 analyze the ability of alternative designs to foster consumer participation and increase total surplus. First, the efficiency of loyalty rewards depend on their specific design. A commitment to the price of repeat purchases can involve substantial efficiency gains by reducing price-cost margins. However, discount policies imply higher future regular prices and are likely to reduce total surplus. Second, firms may prefer to set up inefficient rewards (discounts), especially in those circumstances where a commitment to the price of repeat purchases triggers Coasian dynamics.
\end{abstract}

JEL Classification Numbers: D42, D43, L12, L13

Key words: Loyalty rewards, Coasian dynamics, Price commitment, Coupons

*I would like to thank Roberto Burguet, Adina Claici and participants in 2009 annual meetings of the EEA (Barcelona) and EARIE (Ljubljana) for their useful comments. I also thank the Spanish Ministry of Science and Innovation (ECO2008-08150), Barcelona GSE Research Network, and Generalitat de Catalunya (2009 SGR 1420) for their support. 


\section{Introduction}

All major airlines currently run frequent flyer programs (FFPs) that offer travellers free tickets and class upgrades according to the number of miles or trips flown with them. Hotels, supermarkets and other retailers have also launched similar programs. Some other firms offer much simpler schemes to reward consumer loyalty. Exemplary cases include the classic repeat purchase coupon offered by some manufacturers or the popular buy-ten-andget-one-free type of program, very common among service suppliers, such as golf courts or car washing networks. In all these cases sellers precommit themselves to treat repeat buyers better than newcomers. This is why these pricing schemes are usually labeled "loyalty programs" or "loyalty rewards" (LRs). Some observers have interpreted these schemes as merely quantity discounts (non linear prices). However, this interpretation clouds over the time dimension that is essential in all these examples. Firstly, in some cases the seller commits to the future transaction price, in others (like repeat purchase coupons) the net transaction price is left undetermined. Hence, it is not immediately obvious whether by handing out coupons firms are inducing a lower transaction price for repeat purchases, or a higher price for new customers. Secondly, consumer preferences may change during the time interval between purchases. Thirdly, setting up LRs may affect rivals' future pricing behavior.

The theoretical literature has emphasized the role of LRs as endogenous switching costs. ${ }^{1}$ Most papers have analyzed the role of LRs in some version of the Hotelling framework where consumers' relative preferences are subject to shocks. In this set up LRs allow firms to retain previous customers, even when rival firms offer varieties that better match their current preferences. As a result, LRs are welfare reducing because they cause a mismatch in the allocation of consumers. However, in this view it is unclear whether LRs tend to relax or exacerbate price competition (See, for instance, Banerjee and Summers, 1987; Caminal and Matutes, 1990; Cairns and Gailbraith (1990), Bulkley (1992), Fudenberg and Tirole, 2000, Kim et al., 2001, Caminal and Claici, 2007, Ackerman (2007), Chen and Pearcy (2007), and Fong and Liu,

\footnotetext{
${ }^{1}$ A completely different view of FFPs has recently been put forward by Basso et al. (2009). These programs are alternatively understood as instruments to exploit the agency relationship between employers (who pay for the tickets) and employees (who book travel and enjoy the benefits of LRs). In other words, FFPs are the "bribes" offered to employees to book flights at higher prices.
} 
2009). ${ }^{2}$ It has been shown that the effect of LRs on average prices largely depends on market structure and the particular design of the reward programs. However, the literature has paid very little attention to the endogenous design of LRs, as most papers simply assume that firms are restricted to use a particular specification. ${ }^{3}$

Unfortunately, the available empirical evidence is scarce. In the marketing literature one can find weak evidence of the positive effect of introducing LRs on a firm's market share (See, for instance, Sharp and Sharp, 1997, and Lal and Bell, 2003), although its effect on profitability is less clear. More recently, Hartman and Viard (2008) have empirically challenged the view of LRs as endogenous switching costs. Lederman (2007, and 2008) points to the airline industry and provides convincing evidence on the positive effects of frequent flyer programs on demand and prices, although one can only speculate about the welfare implications of these findings.

The goal of this paper is to contribute to our understanding of LRs beyond the endogenous switching costs motive. In particular, I study the ability of alternative designs to foster consumer participation and increase total surplus. The closest precedent I am aware of was published long time ago: Crémer $(1984)^{4}$. This paper studied a monopolist's incentives to set up LRs in a market for an experience good. An important challenge ever since has been to provide an explanation for the variety of designs that we observe in the real world and determine their welfare implications. In order to accomplish this I examine a stylized two-period monopoly model, which is the simplest set up to demonstrate how firms' optimal design of LRs is affected by the possibility of triggering Coasian dynamics. I also discuss how the main insights extend to a multi-period and multi-firm frameworks.

As in the previous literature, an essential feature of the model is that consumers face some uncertainty about future preferences. In a setting with a homogeneous good, consumers can only be uncertain about their future

\footnotetext{
${ }^{2}$ Armstrong (2006) and Fudenberg and Villas-Boas (2006) discus how this literature fits into the broader theme of behavior-based price discrimination.

${ }^{3}$ Two exceptions are the duopoly models of Kim et al. (2001) and Caminal and Matutes (1990). In the first paper firms are allowed to choose between cash rewards and product rewards. The latter are more efficient in the sense that they imply a lower cost for firms for the same consumer benefit. In either case it is assumed that firms cannot commit to the future transaction price, only to the magnitude of the discount enjoyed by repeat buyers. Caminal and Matutes (1990) show that when firms can choose between committing to the price of repeat purchases and a discount (a coupon) they choose the first option.

${ }^{4}$ See also Bulkley (1992).
} 
valuation of the good, in which case alternative designs of LRs will affect consumer participation differently. However, it will also be argued that, in a competitive setting with differentiated products, it will be important whether consumers are uncertain about their common valuation of the good or about the relative valuation of different varieties. Overall, the model predicts that both the design of the reward program and its welfare implications depend on the amount of uncertainty faced by consumers.

In this sense the subject of this paper is closely related to Chen and Pearcy (2007). While they examine the role of preference uncertainty on dynamic pricing, they have a different goal and set up. In particular, they assume consumers are uncertain about their future relative valuation, and hence LRs become endogenous switching costs. Also, under some circumstances firms may initially find it optimal not to make any commitment and then subsequently treat newcomers better than repeat buyers: play a poaching strategy. In our set up it is always optimal to commit to reward loyalty, and hence the focus is exclusively on the design and efficiency of LRs.

As a benchmark case I consider the optimal monopoly pricing under unlimited commitment capacity. Such an optimal policy clarifies what firms attempt to achieve by setting up reward programs. With respect to the case of no commitment, the optimal policy under full commitment exhibits the following features. First, firms find it optimal to commit to prices equal to marginal cost for repeat purchases, in order to maximize the value of the firm-customer relationship. The seller is able to appropriate the efficiency gains created in the second period through a higher first period price. Second, firms find it optimal to commit to a future price for newcomers, one above the static monopoly price. The reason is that the loss in second period profits caused by distorting the price upwards is more than compensated by the positive effect on first period demand and profits. Third, the gap between the price for newcomers and for repeat buyers raises consumers' willingness to pay in the first period (demand function shifts upwards) and, moreover, it raises price elasticity. Hence, firms find it optimal to serve a larger number of consumers in the first period. Clearly, the first and the third effect lead to efficiency gains, although the second effect has a negative impact on efficiency.

The full commitment case is of course highly unrealistic. Firms may be able to sign implicit or explicit contracts with their current customers, but it is nearly impossible to do it with consumers they have not met yet. Thus, a somewhat more realistic scenario would be one where the monopolist 
enjoys unlimited commitment power with respect current customers, but no commitment power at all with respect future customers. ${ }^{5}$ In this context the monopolist must still make a design choice. It can either commit to the price of repeat purchases, or to a discount policy. In the latter case the level of transaction prices to be paid by loyal consumers is left undetermined. For simplicity I restrict attention to lump-sum discounts.

To illustrate how important is the level of uncertainty about future preferences in shaping the optimal monopoly policy, it is sufficient to restrict attention to the two extreme scenarios.

In the first scenario (Section 3) preferences of individual consumers are independent over time. This implies that the demand functions of repeat and first time buyers exhibit the same price elasticity. If the seller commits to a lower price for repeat buyers then in the second period, it will charge the static monopoly price to newcomers. Expectations of such a high price for newcomers makes it in fact profitable for the seller to commit to a price equal to marginal costs for repeat buyers. From a welfare perspective such a pricing policy is unambiguously beneficial: lower price for repeat buyers, same price for first time buyers in the second period, and higher consumer participation in the first.

Alternatively, the seller may use a discount policy. In this case, it can achieve a rigid combination of a high price for newcomers (higher than the static monopoly price) and a low price for repeat buyers (lower than the static monopoly price). In the particular case where the distribution of consumer valuations is uniform, it turns out that such a discount policy reduces welfare, although for the monopolist this policy is just as profitable as the commitment to the price of repeat purchases.

In the second scenario (Section 4) the correlation between preferences of an individual consumer over time is almost perfect. ${ }^{6}$ In this case, most of the potential first time buyers in the second period have a relatively low willingness to pay. As a result, if the firm decides to commit to a low price for repeat purchases, then in the second period it will also choose a relatively low price for newcomers. In other words, commitment to the price of repeat purchases triggers Coasian dynamics. In the first period the anticipation of

\footnotetext{
${ }^{5}$ Unlimited commitment power regarding current consumers can also be an optimistic description of the real world. In any case, I will not deal here with the issue of how reputation and/or consumer protection laws can help enforcing firms' promises.

${ }^{6}$ Under pefect correlation, individual consumers face no uncertainty and firms have no incentive to set up LRs.
} 
a low price for newcomers more than compensates for the profitable effects of a low price for repeat buyers. In other words, commitment to a low price of repeat purchases will have little effect on first period profits, while drastically reducing second period profits.

In this context, the monopolist may well be motivated to consider using discounts. If the seller offers a lump-sum discount to be applied to repeat purchases, then, along the equilibrium path, the marginal first period consumer has a valuation, $\bar{r}_{1}$, approximately equal to the static monopoly price. In the second period the firm cannot find it optimal to set a regular price that implies a net transaction price for repeat buyers below $\bar{r}_{1}$. If it did, an increase in the regular price would have almost no effect on repeat purchases (almost all repeat buyers have reservation values above $\bar{r}_{1}$ ). At the same time, an increase of the regular price above $\bar{r}_{1}$ will have almost no effect on the purchases of newcomers (very few newcomers have reservation values above $\bar{r}_{1}$ ). Therefore, the optimal monopoly policy consists of a lump-sum discount that implies a higher price for newcomers (the second effect) with a negligible effect on the price for repeat buyers. Finally, the price gap induced by the discount encourages higher sales in the first period (the third effect). The welfare implications of LRs in this case are negative, at least in the case of the uniform distribution.

In Section 5 I will discuss how these results are modified in a competitive environment. It is argued that competition reduces firms' incentives to use efficient designs of LRs, at least if the only source of uncertainty is about common valuations while relative preferences remain constant. A multiperiod framework clearly enlarges the set of possible designs of LRs, but some simple designs like the popular buy-ten-and-get-one-free might also be explained by the attempt of avoiding the negative profit implications of Coasian dynamics.

Some concluding remarks (Section 6) close the paper.

\section{The model}

A profit maximizing monopolist produces a non-durable good at constant marginal cost, which for simplicity is normalized to zero. The market duration is for two periods, labeled 1 and 2. There is a continuum of consumers with mass one; in each period every consumer purchases either one unit or

zero. Consumers are heterogeneous in their valuation of the good. More 
specifically, in the first period each consumer's valuation is a realization of the random variable, $r$, distributed over the interval $[0,1]$ with probability density $f(r)$ and cumulative density function $F(r)$, which is assumed to be twice continuously differentiable. I also assume that the density function does not decrease too quickly, $-2 f(r)-f^{\prime}(r) r<0$. This assumption implies that the one period profit function is strictly concave.

Consumer preferences are imperfectly correlated across periods. In particular, consumer $i$ 's second period valuation, $r_{i 2}$, is equal to her first period valuation, $r_{i 1}$, with probability $\mu$, and an independent random draw from the common density function, $f(r)$, with probability $1-\mu$. The parameter $\mu$ is common knowledge and lies in the interval $[0,1]$.

If consumer $i$ purchases one unit of the good at price $p$, she obtains an instantaneous net utility of $r_{i}-p$. If she does not consume her instantaneous utility is zero.

If the firm is unable to discriminate between repeat buyers and newcomers then it will set the static monopoly price, $p^{m}$, in both periods. That is, $p^{m}$ is the solution to the problem of choosing $p$ in order to maximize $\pi(p) \equiv$ $[1-F(p)] p$. The first order condition characterizes the solution:

$$
\pi^{\prime}\left(p^{m}\right)=1-F\left(p^{m}\right)-f\left(p^{m}\right) p^{m}=0
$$

Also, the static total surplus obtained from transacting at price $p$ is $T S(p) \equiv \int_{p}^{1} r f(r) d r$, and consumer surplus is $C S(p) \equiv \int_{p}^{1}(r-p) f(r) d r$.

For some occasions, and in order to pin down some of the net effects, I will restrict myself to the case of a uniform distribution: $f(r)=1$.

Both the firm and consumers are forward looking, and in period 1 they maximize the expected discounted value of their payoffs using the same factor $\delta, \delta \in[0,1]$.

Most of the insights of the model can be obtained by analyzing two extreme values of $\mu$ : $\mu=0$ (zero correlation in individual preferences) and $\mu=1-\epsilon$, where $\epsilon$ is a positive but arbitrarily small number (almost perfect correlation). It is well-known (See Armstrong, 2006, Section 2) that if consumer preferences are perfectly stable then LRs are irrelevant. This approach will enable us to examine the optimal pricing policy as we approach the scenario with perfectly stable preferences (as $\epsilon$ goes to zero).

A crucial feature of the model is the firm's ability in the second period to price discriminate between repeat buyers and newcomers. On top of that, in the first period the firm has access to alternative commitment devices. 
It has been shown (see, for instance, Chen and Pearcy, 2007) that, in some circumstances, firms may choose not to reward consumer loyalty and rather simply offer better deals to non-customers (poaching strategy). In this model, poaching is never part of the monopolist's optimal plan, and hence we can focus on the optimal design of LRs.

As a benchmark I will consider the case where the firm can commit in the first period to all future prices. A more realistic scenario will be one where the firm has unlimited commitment capacity regarding their current customers, but cannot commit to the price charged in the second period to new customers. Moreover, I will focus attention on two designs of LRs: the firm may choose either the price of repeat purchases or a lump-sum discount with respect to the regular price. The firm can also choose not to commit in the first period, and yet remain free to price discriminate in the second period.

\section{Monopoly pricing under independent pref- erences}

In this section I restrict attention to the case of zero correlation between current and future preferences $\left(\mu=0\right.$.) Let $p_{1}$ be the price charged in the first period, and $p_{2}^{r}$ and $p_{2}^{n}$ the prices charged in the second period to repeat buyers and newcomers, respectively. In the first period, consumer $i$ 's expected utility of purchasing the good is $r_{i 1}-p_{1}+\delta C S\left(p_{2}^{r}\right)$, and the expected utility of not purchasing is $\delta C S\left(p_{2}^{n}\right)$. Thus, all consumers with $r_{i 1} \geq \bar{r}_{1}$ will choose to purchase, where $\bar{r}_{1}$ is given by:

$$
\bar{r}_{1}=p_{1}+\delta\left[C S\left(p_{2}^{n}\right)-C S\left(p_{2}^{r}\right)\right]
$$

Hence, the demand from repeat buyers and newcomers is $q_{2}^{r}=\left[1-F\left(\bar{r}_{1}\right)\right]\left[1-F\left(p_{2}^{r}\right)\right]$ and $q_{2}^{n}=F\left(\bar{r}_{1}\right)\left[1-F\left(p_{2}^{n}\right)\right]$, respectively. The discounted value of profits at time 1 can be written as:

$$
\Pi_{1}\left(p_{1}, p_{2}^{r}, p_{2}^{n}\right)=\left[1-F\left(\bar{r}_{1}\right)\right] p_{1}+\delta\left\{\left[1-F\left(\bar{r}_{1}\right)\right] \pi\left(p_{2}^{r}\right)+F\left(\bar{r}_{1}\right) \pi\left(p_{2}^{n}\right)\right\}
$$




\subsection{The benchmark case}

Suppose that in the first period the firm has full commitment capacity. That is, it can set all prices: $p_{1}, p_{2}^{r}, p_{2}^{n}$. Thus, the monopolist chooses $\left(p_{1}, p_{2}^{r}, p_{2}^{n}\right)$ in order to maximize (2) subject to (1). The main characteristics of the optimal pricing policy are summarized in the following proposition. ${ }^{7}$

Proposition 1 Under $\mu=0$ and full commitment capacity the monopoly solution involves: (a) $p_{2}^{r}=0$,(b) $p_{2}^{n}>p^{m}$, and (c) $\bar{r}_{1}<p^{m}$. More specifically, $p_{2}^{n}$ and $\bar{r}_{1}$ are given respectively by:

$$
1-F\left(p_{2}^{n}\right)-F\left(\bar{r}_{1}\right) f\left(p_{2}^{n}\right) p_{2}^{n}=0
$$

and

$$
1-F\left(\bar{r}_{1}\right)-f\left(\bar{r}_{1}\right) \bar{r}_{1}-f\left(\bar{r}_{1}\right) \delta\left[T S(0)-T S\left(p_{2}^{n}\right)\right]=0
$$

First, the monopolist finds it optimal to commit to a price for repeat buyers equal to marginal cost, which is the price that maximizes the value of the firm-customer relationship. The firm is willing to efficiently price the repeat purchase because it can appropriate these gains by charging a higher price in the first period. Second, the monopolist sets the future price for newcomers above the monopoly price. Starting at $p_{2}^{n}=p^{m}$, a small increase in $p_{2}^{n}$ implies a second order loss in second period profits, but it involves a first order gain in first period profits. The reason is that for consumers a higher $p_{2}^{n}$ makes the first period purchase relatively more attractive. Third, the discrimination between repeat buyers and newcomers raises consumers' willingness to pay in the first period (the demand function shifts upwards), which leads the monopolist to serve a larger number of consumers in the first period. Clearly the first and the third effects are welfare enhancing, but the second is welfare reducing.

In fact, we can compute the increase in total welfare associated to the optimal commitment policy with respect to the case of no discrimination (when the firm charges $p^{m}$ in both periods):

\footnotetext{
${ }^{7}$ If we allow the monopolist not to commit to $\left(p_{2}^{r}, p_{2}^{n}\right)$ in the first period, then the monopolist finds it optimal to set in the second period $p_{2}^{r}=p_{2}^{n}=p^{m}$. The same outcome can be achieved by committing to $p_{2}^{r}=p_{2}^{n}=p^{m}$ in the first period. Thus, expanding the strategy set to include no commitment in the first period is redundant. In other words, the ability to price discriminate between repeat buyers and newcomers is irrelevant in the absence of commitment.
} 


$$
\Delta W=\delta\left[1-F\left(\bar{r}_{1}\right)\right] \int_{0}^{p^{m}} r f(r) d r-\delta F\left(\bar{r}_{1}\right) \int_{p^{m}}^{p_{2}^{n}} r f(r) d r+\int_{\bar{r}_{1}}^{p^{m}} r f(r) d r
$$

The three terms of the right hand side correspond to the three effects discussed above.

If we restrict attention to the uniform distribution case, then the first two terms of equation (5) can be written as:

$$
\Delta W=\delta\left\{\int_{0}^{\frac{1}{2}} r d r-\bar{r}_{1} \int_{0}^{\frac{1}{1+\bar{r}_{1}}} r d r\right\}=\frac{\delta\left(1-\bar{r}_{1}\right)^{2}}{8\left(1+\bar{r}_{1}\right)^{2}}>0
$$

Since the third effect is always positive, the overall welfare effect is also positive. Summarizing:

Remark 2 If $f(r)=1$ then total surplus under the full commitment policy is higher than under no discrimination.

\subsection{Commitment to the price of repeat purchases}

In the real world most firms seem able to commit to their future pricing policy with respect to their current customers, or at least are able to lay down significant restrictions on their future pricing behavior. In the extreme case, sellers can sign legally enforceable, long-term contracts with current buyers. However, it is much less plausible that firms do this with consumers they still have not interacted with. A similar argument applies to implicit contracts that rely on reputation. ${ }^{8}$ In this and the next subsections I take the view that the monopolist can commit to a particular scheme to reward consumer loyalty, but it must leave undetermined the price to be paid by newcomers. In particular, in this subsection the monopolist chooses $\left(p_{1}, p_{2}^{r}\right)$ in the first period and $p_{2}^{n}$ in the second. ${ }^{9}$ The optimal pricing policy is

\footnotetext{
${ }^{8}$ In the real world LR are not always fully specified and firms maintain some discretionary power. For instance, airlines unilaterally change from time to time the conditions to earn and redeem frequent flyer miles. In this paper I entirely ignore any limitation to firms' commitment power with respect to their current customers.

${ }^{9}$ Once again, we could allow the monopolist not to commit to $p_{2}^{r}$ in the first period. In this case, the monopolist finds it optimal to set in the second period $p_{2}^{r}=p_{2}^{n}=p^{m}$. The same outcome can be achieved by committing to $p_{2}^{r}=p^{m}$ in the first period, which is shown to be a dominated strategy.
} 
summarized in the following proposition:

Proposition 3 Under $\mu=0$, and if the firm can only commit to the price for repeat buyers, the monopoly solution includes: (a) $p_{2}^{r}=0$, (b) $p_{2}^{n}=p^{m}$, and (c) $\bar{r}_{1}<p^{m}$. Consequently, the firm's ability to commit to the price of repeat purchases raises total welfare. More specifically, $\bar{r}_{1}$ is given by:

$$
1-F\left(\bar{r}_{1}\right)-f\left(\bar{r}_{1}\right) \bar{r}_{1}-f\left(\bar{r}_{1}\right) \delta\left[T S(0)-T S\left(p^{m}\right)\right]=0
$$

The intuition behind these results is rather straightforward. In the second period, the monopolist finds it optimal to set the static monopoly price to newcomers, since $p_{2}^{n}$ is chosen in order to maximize $F\left(\bar{r}_{1}\right)\left[1-F\left(p_{2}^{n}\right)\right] p_{2}^{n}$. However, the incentives to adopt a marginal cost pricing rule for repeat purchases remain constant. Since $p_{2}^{n}=p^{m}>p_{2}^{r}=0$, the demand function in the first period shifts upwards with respect to the static case and, as a result, the optimal $p_{1}$ involves higher sales in the first period than in the absence of commitment. In other words, in this case we obtain the first and third effects identified in the previous subsection, both with positive welfare implications, but the second effect is null. More specifically, the increase in total welfare associated to the optimal commitment policy (with respect to the case of no discrimination) can be written as:

$$
\Delta W=\delta\left[1-F\left(\bar{r}_{1}\right)\right] \int_{0}^{p^{m}} r f(r) d r+\int_{\bar{r}_{1}}^{p^{m}} r f(r) d r>0
$$

\subsection{Discounts}

Suppose now that in the first period the seller offers its customers a fixed discount (coupon) of face value $c$. This implies that in the second period the net transaction price for repeat buyers is $p_{2}^{r}=p_{2}^{n}-c$, where $p_{2}^{n}$ is selected in the second period. In particular, the firm chooses $p_{2}^{n}$ in order to maximize (even in the case $c=0$ ):

$$
\pi_{2}=\left[1-F\left(\bar{r}_{1}\right)\right] \pi\left(p_{2}^{n}-c\right)+F\left(\bar{r}_{1}\right) \pi\left(p_{2}^{n}\right)
$$

In case an interior solution exists, it is given by:

$$
\left[1-F\left(\bar{r}_{1}\right)\right] \pi^{\prime}\left(p_{2}^{n}-c\right)+F\left(\bar{r}_{1}\right) \pi^{\prime}\left(p_{2}^{n}\right)=0
$$


Thus, in this case $p_{2}^{n}>p^{m}>p_{2}^{n}-c$. The firm might have incentives to choose a corner solution where newcomers are not served: $p_{2}^{n} \geq 1$. In such a corner solution the firm finds it optimal to set the static monopoly price to repeat buyers: $p_{2}^{n}-c=p^{m}$. Thus, the equilibrium value of $p_{2}^{n}$ will be given by equation (6), provided the following constraint is satisfied:

$$
\left[1-F\left(\bar{r}_{1}\right)\right] \pi\left(p_{2}^{n}-c\right)+F\left(\bar{r}_{1}\right) \pi\left(p_{2}^{n}\right) \geq\left[1-F\left(\bar{r}_{1}\right)\right] \pi\left(p^{m}\right)
$$

Thus, by using discounts the monopolist can achieve a certain commitment to a lower price for repeat buyers and a higher price for newcomers (first and second effects), provided the solution is interior. If the monopolist finds it optimal to exclude newcomers in the second period, then a discount policy involves the second effect, but not the first. Finally, because of the different expected consumer surplus obtained by repeat buyers and newcomers, the monopolist sets a first period price so it serves more first period consumers than in the no commitment case (the third effect). More specifically, in the first period, if the monopolist anticipates an interior solution in the second period, then it chooses $p_{1}$ and $c$ in order to maximize:

$$
\Pi_{1}=\left[1-F\left(\bar{r}_{1}\right)\right] p_{1}+\delta\left\{F\left(\bar{r}_{1}\right) \pi\left(p_{2}^{n}\right)+\left[1-F\left(\bar{r}_{1}\right)\right] \pi\left(p_{2}^{n}-c\right)\right\}
$$

subject to $\bar{r}_{1}=p_{1}+\delta\left[C S\left(p_{2}^{n}\right)-C S\left(p_{2}^{n}-c\right)\right]$ and subject to $p_{2}^{n}$ being determined by equation (6). The solution involves $\bar{r}_{1}<p^{m}$. Alternatively, if in the second period newcomers are excluded, then the first period objective function becomes:

$$
\Pi_{1}=\left[1-F\left(\bar{r}_{1}\right)\right]\left[\bar{r}_{1}+\delta T S\left(p^{m}\right)\right]
$$

Also in this case, the monopoly solution would involve $\bar{r}_{1}<p^{m}$.

The following proposition summarizes this discussion.

Proposition 4 If $\mu=0$ the monopolist's optimal discount policy implies: (i) $p_{2}^{r} \leq p^{m}$, (ii) $p_{2}^{n}>p^{m}$, and (iii) $\bar{r}_{1}<p^{m}$.

Once again, it is impossible to compare in general the size of the second (negative) effect to the size of the first and third effects (positive). If we restrict attention to the uniform density case then we can offer an unambiguous answer (For the proof see Appendix 1): 
Remark 5 If $f(r)=1$ the optimal discount policy reduces total surplus.

The main reason a discount policy reduces total surplus is the concavity of total surplus as a function of price. In the absence of commitment in the second period a monopolist sets a price equal to $\frac{1}{2}$. In contrast, under the optimal discount policy the price charged to newcomers is raised above $\frac{1}{2}$ more than the reduction obtained by repeat buyers. As a result, total surplus generated in the second period is lower than in the absence of commitment (the sum of the first and second effects has a negative sign). Finally, the positive welfare effect generated in the first period, associated to higher consumer participation, is not capable of reversing this result. ${ }^{10}$

\subsection{Comparing alternative pricing schemes}

After characterizing the optimal price commitment and discount policies in the last two subsections, we can now compare the preferred policy from a social (total surplus) and private (monopoly profits) viewpoints. In particular, we can consider the following three scenarios: (a) commitment to the repeat purchase price, $p_{2}^{r}$, (b) commitment to a lump-sum coupon, $c$, and (c) no commitment (which, in this case, is equivalent to no price discrimination).

Once again, functional forms are crucial to pin down the results. From Proposition 3 and Remark 4 it follows that:

Remark 6 If $f(r)=1$ the social planner prefers the price commitment policy, (next) the no commitment scenario, and (finally) the discount policy.

Let us now turn to private incentives, It is important to remember that no commitment can be implemented by setting $p_{2}^{r}=p^{m}$, or $c=0$. Since the monopolist does not find neither of these two options optimal, then the no commitment scenario is clearly dominated by either of the two alternative scenarios. The following result is proved in Appendix 2:

Remark 7 If $f(r)=1$ the monopolist is indifferent between committing to the price of repeat purchases and a discount policy, and both are strictly preferred to the no commitment scenario.

\footnotetext{
${ }^{10}$ As discussed in the Appendix, the impact of the optimal discount policy on welfare is negative but of second order. This suggests that may there exist alternative functional forms under which a discount policy may increase welfare.
} 
Thus, in the uniform distribution (linear demand) case the monopolist is indifferent between these two alternative designs of LRs. However, from an efficiency point of view discount policies should not be allowed and price schemes that involve a commitment to the price of repeat purchases should be promoted.

The uniform distribution case is actually a borderline case (See Appendix $3)$ :

Remark 8 There exist density functions for which the monopolist either strictly prefers committing to the price of repeat purchases over a discount policy and viceversa.

In sum, the main conclusion of this subsection is that, under independent preferences, a monopolist may have incentives to choose a design of LRs that increases welfare, for some density functions, but it may also choose a design with much less favorable welfare implications, for other functions.

\section{Monopoly pricing under almost perfectly correlated preferences}

This section deals with the case where preferences of an individual consumer are almost perfectly correlated: $\mu=1-\epsilon$, where $\epsilon$ is an arbitrarily small, positive number.

The demand in the second period from repeat buyers, $q_{2}^{r}$, is given by:

$$
q_{2}^{r}=\left\{\begin{array}{l}
{\left[1-\epsilon F\left(\bar{r}_{1}\right)\right]\left[1-F\left(p_{2}^{r}\right)\right] \text { if } 1 \geq p_{2}^{r} \geq \bar{r}_{1}} \\
{\left[1-F\left(\bar{r}_{1}\right)\right]\left[1-\epsilon F\left(p_{2}^{r}\right)\right], \text { if } 0 \leq p_{2}^{r} \leq \bar{r}_{1}}
\end{array}\right.
$$

and the demand from newcomers, $q_{2}^{n}$ :

$$
q_{2}^{n}=\left\{\begin{array}{c}
\epsilon F\left(\bar{r}_{1}\right)\left[1-F\left(p_{2}^{n}\right)\right] \text { if } 1 \geq p_{2}^{n} \geq \bar{r}_{1} \\
F\left(\bar{r}_{1}\right)-\left[1-\epsilon+\epsilon F\left(\bar{r}_{1}\right)\right] F\left(p_{2}^{n}\right), \text { if } 0 \leq p_{2}^{n} \leq \bar{r}_{1}
\end{array}\right.
$$

Thus, at a price equal to $\bar{r}_{1}$ these demand functions are not differentiable. The price elasticity of the demand from repeat buyers is higher for price increases than for price decreases, but the reverse in the demand from newcomers. 
In order to simplify the presentation, I assume that the market is semianonymous (Fudenberg and Tirole, 1998). That is, price discrimination requires the voluntary participation of consumers. For instance, the seller may be able to distinguish repeat buyers from newcomers if they hand in a coupon they obtained with their first period purchase, or if they voluntarily registered in the reward program. Therefore, we can restrict attention to price schemes that truly reward loyalty $\left(p_{2}^{r} \leq p_{2}^{n}\right)$. Also, if the firm does not make any commitment in the first period then it would set the static monopoly price in each period. I argue below that the same qualitative results are obtained in case of an identified customers market (in which case the seller can price discriminate in the second period against former customers).

\subsection{The benchmark case}

Let us reconsider the full commitment case in which the monopoly can choose all prices in the first period. The characterization of the indifferent consumer in the first period depends on how her willingness to pay in the first period, $\bar{r}_{1}$, compares to second period prices. In particular, there are three possible cases: (i) $\bar{r}_{1} \leq p_{2}^{r} \leq p_{2}^{n}$, (ii) $p_{2}^{r}<\bar{r}_{1} \leq p_{2}^{n}$ and (iii) $p_{2}^{r} \leq p_{2}^{n}<\bar{r}_{1}$. In Appendix 4 I prove the following lemma:

Lemma 9 If $\mu$ is arbitrarily close to 1 and under full commitment capacity, the monopoly solution satisfies: $p_{2}^{r}<\bar{r}_{1} \leq p_{2}^{n}$.

Thus, in case (ii) we have: ${ }^{11}$

$$
\bar{r}_{1}=\frac{1}{1+\delta(1-\epsilon)}\left\{p_{1}+\delta(1-\epsilon) p_{2}^{r}+\delta \epsilon\left[C S\left(p_{2}^{n}\right)-C S\left(p_{2}^{r}\right)\right]\right\}
$$

The firm's present value of profits in the first period is:

$$
\Pi_{1}\left(p_{1}, p_{2}^{r}, p_{2}^{n}\right)=\left[1-F\left(\bar{r}_{1}\right)\right] p_{1}+\delta\left\{\left[1-F\left(\bar{r}_{1}\right)\right]\left[1-\epsilon F\left(p_{2}^{r}\right)\right] p_{2}^{r}+\epsilon F\left(\bar{r}_{1}\right) \pi\left(p_{2}^{n}\right)\right\}
$$

The next proposition characterizes the optimal monopoly strategy under full commitment.

\footnotetext{
${ }^{11}$ In an identified customers market other cases are also feasible. However, it can be shown that the seller does not find it optimal to commit to a policy with $p_{2}^{n}<p_{2}^{r}$. Hence, the lemma would still hold.
} 
Proposition 10 If $\mu$ is arbitrarily close to 1 and under full commitment capacity, the monopoly solution involves: (a) $p_{2}^{r}=0$, (b) $p_{2}^{n}>p^{m}$, and (c) $\bar{r}_{1}<p^{m}$.

The equations that characterize $p_{2}^{n}$ and $\bar{r}_{1}$ are respectively:

$$
\begin{gathered}
1-F\left(p_{2}^{n}\right)-F\left(\bar{r}_{1}\right) f\left(p_{2}^{n}\right) p_{2}^{n}=0 \\
1-F\left(\bar{r}_{1}\right)-f\left(\bar{r}_{1}\right) \bar{r}_{1}-f\left(\bar{r}_{1}\right) \frac{\delta \epsilon}{1+\delta(1-\epsilon)}\left[T S(0)-T S\left(p_{2}^{n}\right)\right]=0
\end{gathered}
$$

If we take the limit as $\epsilon$ goes to zero, then $\bar{r}_{1}$ goes to $p^{m}$ and $p_{2}^{n}$ goes to $p^{s}$, where $p^{s}$ is implicitly given by:

$$
1-F\left(p^{s}\right)-F\left(p^{m}\right) f\left(p^{s}\right) p^{s}=0
$$

Given that $F\left(p^{m}\right)<1$, equation (7) implies that $p^{s}>p^{m}$. Thus, the monopolist's optimal policy for $\mu=1-\epsilon$ is qualitatively identical to the one for $\mu=0$.

If we take the limit as $\epsilon$ goes to zero, then the monopoly solution becomes $p_{1}=(1+\delta) p^{m}, \bar{r}_{1}=p^{m}, p_{2}^{r}=0, p_{2}^{n}=p^{s}$. In fact, if $\epsilon=0$ the monopolist is indifferent between the previous solution and the repetition of the static monopoly price: $p_{1}=\bar{r}_{1}=p_{2}^{r}=p_{2}^{n}=p^{m}$. However, only the former is robust to a small amount of uncertainty $(\epsilon>0)$.

\subsection{Commitment to the price of repeat purchases}

The seller chooses $\left(p_{1}, p_{2}^{r}\right)$ in the first period and $p_{2}^{n}$ in the second.

When individual preferences are highly correlated the firm's commitment to the price of repeat purchases generates Coasian dynamics. Almost all potential new customers in the second period have a willingness to pay lower than $\bar{r}_{1}$. As a result the firm has strong incentives to set a relatively low $p_{2}^{n}$, in particular lower than $\bar{r}_{1}$. More specifically, $p_{2}^{n}$ is the solution of the following optimization problem: choose $p$ in order to maximize:

$$
\pi_{2}^{n}(p)=\left\{F\left(\bar{r}_{1}\right)-\left[1-\epsilon+\epsilon F\left(\bar{r}_{1}\right)\right] F(p)\right\} p
$$

subject to $\bar{r}_{1} \geq p \geq p_{2}^{r}$. The first order condition of an interior solution is: 


$$
F\left(\bar{r}_{1}\right)-\left[1-\epsilon+\epsilon F\left(\bar{r}_{1}\right)\right]\left[F\left(p_{2}^{n}\right)+f\left(p_{2}^{n}\right) p_{2}^{n}\right]=0
$$

Since $\epsilon$ is an arbitrarily small number then $0<p_{2}^{n}<\bar{r}_{1}$. Suppose that in the first period the firm chooses to commit to the price for repeat purchases. That is, $p_{1}$ and $p_{2}^{r}$ are chosen in order to maximize:

$$
\Pi_{1}\left(p_{1}, p_{2}^{r}, p_{2}^{n}\right)=\left[1-F\left(\bar{r}_{1}\right)\right] p_{1}+\delta\left\{\left[1-F\left(\bar{r}_{1}\right)\right]\left[1-\epsilon F\left(p_{2}^{r}\right)\right] p_{2}^{r}+\pi_{2}^{n}\left(p_{2}^{n}\right)\right\}
$$

where

$$
\bar{r}_{1}=p_{1}+\delta \epsilon\left[C S\left(p_{2}^{n}\right)-C S\left(p_{2}^{r}\right)\right]+\delta(1-\epsilon)\left(p_{2}^{r}-p_{2}^{n}\right)
$$

The solution includes $p_{2}^{r}=0$ and $\bar{r}_{1}$ is implicitly given by:

$$
1-F\left(\bar{r}_{1}\right)-f\left(\bar{r}_{1}\right)\left\{\bar{r}_{1}+\delta \epsilon\left[T S(0)-T S\left(p_{2}^{n}\right)\right]+\delta(1-\epsilon) p_{2}^{n}\right\}=0
$$

Note that $0<\bar{r}_{1}<p^{m}$ and, as $\epsilon$ goes to zero, $\bar{r}_{1}$ converges to a value strictly below $p^{m}$. In the limit as $\epsilon$ goes to zero the firm's profits become:

$$
\Pi_{1}=\pi\left(\bar{r}_{1}\right)+\delta \pi\left(p_{2}^{n}\right)<<(1+\delta) \pi\left(p^{m}\right)
$$

where $\bar{r}_{1}$ and $p_{2}^{n}$ are given by equations (8) and (9) evaluated at $\epsilon=0$.

Therefore, in this case if the firm commits to the price of repeat purchases, then it obtains a level of profits lower than if it chooses not to commit.

All this discussion is encapsulated in the following proposition: ${ }^{12}$

Proposition 11 If $\mu$ is arbitrarily close to 1 and the firm's commitment capacity is restricted to the price of repeat purchases, then the monopolist prefers not to use such a commitment capacity and set the static monopoly price in both periods.

\footnotetext{
${ }^{12}$ In an identified customers market, the monopolist may prefer to commit to the price for repeat purchase over no commitment. However, as discussed below, both options are dominated by a discount policy.
} 


\subsection{Discounts}

The seller sets $\left(p_{1}, c\right)$ in the first period and $p_{2}^{n}$ in the second, in the understanding that $p_{2}^{r}=p_{2}^{n}-c$.

Given the discount $c$, in the second period the firm chooses $p_{2}^{n}$ in order to maximize second period profits. In principle there are three possible cases: (i) $\bar{r}_{1} \leq p_{2}^{r} \leq p_{2}^{n}$, (ii) $p_{2}^{r}<\bar{r}_{1} \leq p_{2}^{n}$ and (iii) $p_{2}^{r} \leq p_{2}^{n}<\bar{r}_{1}$. The next Lemma (See Appendix 5) allows us to concentrate on case (i):

Lemma 12 The optimal discount policy involves $\bar{r}_{1} \leq p_{2}^{r}=p_{2}^{n}-c$.

The intuition here is the following. Most repeat buyers have a reservation price higher than $\bar{r}_{1}$. Thus, if the firm lowers $p_{2}^{n}$ below $c+\bar{r}_{1}$ it will attract very few repeat buyers; hence it cannot be an optimal strategy.

Thus, it follows that in the second period $p_{2}^{n}$ is the solution to maximize:

$$
\Pi_{2}=\left[1-\epsilon F\left(\bar{r}_{1}\right)\right] \pi\left(p_{2}^{n}-c\right)+\epsilon F\left(\bar{r}_{1}\right) \pi\left(p_{2}^{n}\right)
$$

subject to $p_{2}^{n}-c \geq \bar{r}_{1}$.

The first order condition of an interior solution is:

$$
\left[1-\epsilon F\left(\bar{r}_{1}\right)\right] \pi^{\prime}\left(p_{2}^{n}-c\right)+\epsilon F\left(\bar{r}_{1}\right) \pi^{\prime}\left(p_{2}^{n}\right)=0
$$

Thus, $p_{2}^{n}-c$ is below but arbitrarily close to $p^{m}$ and $p_{2}^{n}>p^{m}$.

Suppose that in the second period the constraint $\bar{r}_{1} \leq p_{2}^{n}-c$ is not binding. Then, the firm's optimization problem in the first period consists of choosing $\left(p_{1}, c\right)$ in order to maximize:

$$
\Pi_{1}=\left[1-F\left(\bar{r}_{1}\right)\right] p_{1}+\delta\left\{\left[1-\epsilon F\left(\bar{r}_{1}\right)\right] \pi\left(p_{2}^{n}-c\right)+\epsilon F\left(\bar{r}_{1}\right) \pi\left(p_{2}^{n}\right)\right\}
$$

where

$$
\bar{r}_{1}=p_{1}+\delta \epsilon\left[C S\left(p_{2}^{n}\right)-C S\left(p_{2}^{n}-c\right)\right]
$$

and $p_{2}^{n}$ is given by equation (10). The first order conditions with respect to $p_{1}$ and $c$ can be written, respectively:

$$
1-F\left(\bar{r}_{1}\right)-f\left(\bar{r}_{1}\right)\left\{\bar{r}_{1}+\delta \epsilon\left[T S\left(p_{2}^{n}-c\right)-T S\left(p_{2}^{n}\right)\right]\right\}=0
$$


$F\left(\bar{r}_{1}\right) \pi^{\prime}\left(p_{2}^{n}\right)-\left[1-F\left(\bar{r}_{1}\right)\right]\left\{\left[1-F\left(p_{2}^{n}-c\right)\right] \frac{d\left(p_{2}^{n}-c\right)}{d c}-\left[1-F\left(p_{2}^{n}\right)\right] \frac{d p_{2}^{n}}{d c}\right\}=0$

If we take the limit as $\epsilon$ goes to zero, then $p_{2}^{n}-c$ and $\bar{r}_{1}$ go to $p^{m}, \frac{d p_{2}^{n}}{d c}$ goes to 1 , and hence $p_{2}^{n}$ goes to $p^{s}$, defined in equation (7), $p^{s}>p^{m}$.

Suppose now that in the second period the constraint is binding: $p_{2}^{n}=$ $\bar{r}_{1}+c$. Then the optimization problem can be reformulated as choosing $\left(p_{1}, c\right)$ in order to maximize:

$$
\Pi_{1}=\left[1-F\left(\bar{r}_{1}\right)\right] p_{1}+\delta\left\{\left[1-\epsilon F\left(\bar{r}_{1}\right)\right] \pi\left(\bar{r}_{1}\right)+\epsilon F\left(\bar{r}_{1}\right) \pi\left(\bar{r}_{1}+c\right)\right\}
$$

where

$$
\bar{r}_{1}=p_{1}+\delta \epsilon\left[C S\left(\bar{r}_{1}+c\right)-C S\left(\bar{r}_{1}\right)\right]
$$

In this case the solution shares the same qualitative properties. All this discussion is summarized in the next proposition.

Proposition 13 If $\mu$ is arbitrarily close to 1 the monopolist's optimal discount policy involves: (a) $p_{2}^{r}$ is below but arbitrarily close to $p^{m}$, (b) $p_{2}^{n}$ is arbitrarily close to $p^{s}$ and hence higher than $p^{m}$, and (c) $\bar{r}_{1}<p^{m}$.

It is important to note that $c$ converges to a strictly positive number $\left(p^{s}-p^{m}\right)$ as $\epsilon$ goes to zero. This implies that for any $\epsilon>0$ the optimal discount policy involves higher profits than in the case of no commitment $(c=0)$. Thus,

Remark 14 If $\mu$ is arbitrarily close to 1, the monopolist prefers a discount policy over a commitment to the price of repeat purchases.

In an identified customers market, if the monopolist does not make any commitment in the first period then it will have incentives to price discriminate in the second period in favor of newcomers. This reduces ex-ante profits far below the level obtained under no discrimination. Consequently, the monopolist still prefers to set $c>0$ in the first period.

In terms of the three effects discussed above, the first effect (lower price for repeat purchases) is negligible in the optimal discount policy. More specifically, its impact on welfare can be written as: 


$$
\Delta W=\delta \epsilon \int_{p_{2}^{n}-c}^{p^{m}} r f(r) d r-\delta \epsilon F\left(\bar{r}_{1}\right) \int_{p^{m}}^{p_{2}^{n}} r f(r) d r+\int_{\bar{r}_{1}}^{p^{m}} r f(r) d r
$$

In the case of a uniform distribution $p^{m}=\frac{1}{2}, p^{s}=\frac{2}{3}$. Thus, disregarding all quadratic and higher order terms we can write:

$$
\Delta W \approx-\delta \epsilon \bar{r}_{1} \int_{\frac{1}{2}}^{\frac{2}{3}} r d r+\int_{\bar{r}_{1}}^{\frac{1}{2}} r d r
$$

Since $\bar{r}_{1} \approx \frac{1}{2}-\delta \epsilon \frac{7}{144}$, then $\Delta W \approx-\frac{7}{288} \delta \epsilon<0$.

Remark 15 If $f(r)=1$, then the optimal discount policy reduces total surplus.

Summarizing, if individual preferences exhibit very high serial correlation then the monopolist prefers not to commit to the repeat purchase price because this triggers Coasian dynamics. However, the monopolist finds it optimal to commit to a relatively large lump-sum coupon, which does not significantly reduce the repeat purchase price but does raise the price charged to newcomers. Under a uniform distribution, the monopolist's favorite design of LRs actually reduces total welfare.

\section{Discussion}

In this paper the analysis has been conducted in a stylized, two-period monopoly model. How do firms' incentives to introduce LRs change in a competitive environment? What kind of alternative designs might arise in equilibrium in a multi-period framework?

\subsection{Inter-firm competition}

As discussed in the introduction, the literature has focused on the role of LRs in a competitive set up (typically, a duopoly), where consumers are uncertain about their relative valuations (their absolute valuations are assumed to be of sufficient magnitude so that in equilibrium all consumers participate in the market). LRs create endogenous switching costs and allow firms to retain 
some of their customers, even when their current preferences better match with the characteristics of the specific product offered by rival firms. For example, some travellers may remain loyal to a particular airline because of their status in its frequent flyer program, despite of the fact that another airline offers better schedules and connections for their current trip.

Most of the insights of the current model are likely to extend to a multifirm environment, provided consumers are uncertain only about their absolute valuation, and hence their participation in the market. In particular, firms' incentives to set up LRs will closely resemble those analyzed in this paper. However, inter-firm competition will bring about additional effects.

Consider a monopolistic competitive market: each firm will not anticipate any reaction to its choice of LRs program. However, in this case whether or not other firms are offering LRs will certainly affect individual incentives to do so. Suppose a particular firm faces a set of rivals that do not reward loyalty. If the firm commits to the price of repeat purchases, this will trigger Coasian dynamics for two complementary reasons: (1) in order to lure consumers with a high relative preference for the firm's product but a relatively low willingness to pay (like in the model of this paper), but also (2) in order to attract customers of rival firms (low relative preference but high willingness to pay). In contrast, if rival firms actually commit to a low price for their repeat buyers it becomes more difficult in the second period to steal business from rival firms, and hence incentives to commit to a low price for repeat purchases are enhanced. LRs programs are thus very likely to be strategic complements and a model like this may exhibit a multiplicity of equilibria.

In an oligopolistic market each firm will try to anticipate the rivals' reaction to its LRs program. Such an strategic effect may also influence equilibrium decisions in complex ways which are exceedingly more difficult to visualize.

\subsection{A multi-period framework}

In the two-period framework it was shown that a monopolist may not find it optimal to commit to a low price for repeat buyers due to the fact that such a commitment will imply a low regular price in the future. The two-period framework in a way exacerbates the strength of Coasian dynamics. Consider a multi-period framework. A monopolist could set up a loyalty program that offers consumers the right to purchase the good at a low price after $n$ purchases at the regular price (buy-ten-and-get-one-free kind of program.) 
In this case most repeat buyers pay the regular price in a given period, since only a fraction $\frac{1}{n+1}$ (in average) are exempted. As a result, incentives to set a low regular price are significantly reduced (Coasian dynamics are avoided). Consequently, firms may find such a design profitable, at least compared with the no commitment case.

Some of the insights of a multi-period framework might be made in the two-period set up by allowing for random rewards. In this paper sellers are restricted to deterministic schemes. Suppose we let the monopolist commit to marginal cost pricing for repeat purchases only for a fraction $\alpha$ of first period customers. By choosing $\alpha$ properly Coasian dynamics can be avoided, and such a policy could become profitable even if $\mu$ is close to 1 . Unfortunately, a full characterization of the optimal value of $\alpha$ presents some technical difficulties and is left for future research.

\section{Concluding remarks}

In this paper I show that the design of LRs significantly matters for efficiency. In particular, a commitment to the price of repeat purchases may bring about large efficiency gains by fostering consumer participation, and hence eliminating some of the inefficiencies associated to market power. However, this type of LRs may not be incentive compatible, in the sense that firms may prefer to use discount policies, which in many cases reduce total welfare with respect to the case of the absence of any LRs. Thus, the paper contributes to our understanding of the mechanisms (other than the creation of switching costs) by which LRs affect efficiency. It also helps us to explain the heterogeneity of designs observed in the real world (emphasizing the role of the degree of uncertainty faced by individual consumers about their future preferences).

The highly stilized model used in this paper is meant to capture qualitative effects, with no intention of making any quantitative claims. However, if taken literally some of the predictions of the model seem exaggerated when compared to real world observations. In particular, LRs have a large effect on the variance of transaction prices that a consumer experiences over time. For instance, the commitment to the price for repeat purchases looks very much like a two-part tariff. In the first period consumers pay a high price, and in the second a price equal to marginal cost. In some cases, the optimal discount policy also involves a discount equivalent to the static monopoly 
price-cost margin.

The "quantitative" predictions appear more moderate when we extend the model in several directions. In particular, let us discuss several scenarios. First (see the previous section), in a multi-period framework it may be optimal to set up an scheme that rewards loyalty only after the consumer has made a fixed number of purchases. Second, if we let product quality in the second period be endogenous, then LRs may exacerbate the moral hazard problem. More specifically, if the firm commits to a price equal to marginal cost for repeat buyers but cannot commit to future quality standards, then the incentives to maintain those standards in the second period will likely deteriorate. As a result, the firm may prefer to reduce the magnitude of LRs in order to alleviate the quality underinvestment problem. Third, it would be interesting to investigate the coexistence of consumers with different time horizons. For instance, consider a multi-period framework where in each period a new cohort of consumers with a two-period horizon enters the market. Suppose the firm is unable to distinguish between consumers with different "ages". Then, blind to differential generations firms will no longer be willing to commit to marginal cost pricing for repeat buyers. This will be because they will not be able to capture the entire surplus through the first period price, which in this case will be closer to the static monopoly price. ${ }^{13}$

I have argued that all these considerations tend to reduce the magnitude of LRs, at least if we restrict ourselves to a particular design (commitment to the price of repeat purchases.) Future research should address how all these considerations affect the optimal design.

\section{$7 \quad$ References}

Ackerman, P. (2007), Loyalty Rewards and Monopoly Pricing, mimeo University of Bern.

Armstrong, M. (2006), Recent Developments in the Economics of Price Discrimination, Chapter 4 Advances in Economics and Econometrics: Theory and Applications, Ninth World Congress of the Econometric Society, Vol. II. Eds Blundell, Newry, and Persson. Cambridge University Press.

Banerjee, A. and L. Summers (1987), On Frequent Flyer Programs and Other Loyalty-Inducing Arrangements, Harvard Institute for Economic Research, working paper No. 1337.

\footnotetext{
${ }^{13}$ See Caminal and Claici (2007) for a similar result in a related framework.
} 
Basso, L., M. Clements, and T. Ross (2009), Moral hazard and Customer Loyalty Programs, American Economic Journal: Microeconomics 1 (1), 101123.

Bulkley, G. (1992), The role of loyalty discounts when consumers are uncertain of the value of repeat purchases, International Journal of Industrial Organization, 10, 91-101.

Cairns, T., Galbraith, J. (1990), Artificial compatibility, barriers to entry, and frequent-flyer programs. Canadian Journal of Economics 23 (4), 807-816.

Caminal, R. and A. Claici (2007), Are loyalty-rewarding pricing schemes anti-competitive? International Journal of Industrial Organization, 25, 657674 .

Caminal, R. and C. Matutes (1990), Endogenous Switching Costs in a Duopoly Model, International Journal of Industrial Organization, 8(3), 353373.

Chen, Y. and J. Pearcy (2007), Dynamic Pricing: When to Entice Brand Switching And When To Reward Consumer Loyalty, mimeo University of Colorado.

Crémer, J. (1984), On the Economics of Repeat Buying, Rand Journal of Economics, 15(3), 396-403.

Fong, Y. and Q. Liu (2009), Loyalty Rewards Facilitate Collusion, mimeo Northwestern University.

Fudenberg, D. and J. Tirole (1998), Upgrades, tradeins, and buybacks, Rand Journal of Economics 29, 235-258.

Fudenberg, D. and J. Tirole (2000), Customer Poaching and Brand Switching, Rand Journal of Economics, 31, 634-657.

Fudenberg, D. and J.M. Villas-Boas (2006), Behavior-Based Price Discrimination and Customer Recognition, in Handbook of Economics and Information Systems (T.J. Hendershott, Ed.), pp. 377-436.

Hartman, W. and V.B. Viard (2008), Do Frequency Reward Programs Create Switching Costs? A Dynamic Structural Analysis of Demand in a Reward Program, Quantitative Marketing and Economics 6(2), 109-137.

Kim, B., Shi, M. and K. Srinivasan (2001), Reward Programs and Tacit Collusion, Marketing Science, 20 (2), 99-120.

Lal, R. and D. Bell (2003), The impact of frequent shopper programs in grocery retailing. Quantitative Marketing and Economics 1, 179-202.

Lederman, M. (2007), Do Enhancements to Loyalty Programs Affect Demand? The Impact of International Frequent Flyer Partnerships on Domestic Airline Demand, Rand Journal of Economics 38(4), 1134-1158. 
Lederman, M. (2008), Are Frequent Flyer Programs a Cause of the "Hub Premium"?, Journal of Economics and Management Strategy 17(1), 35-66.

Sharp, B. and A. Sharp (1997), Loyalty programs and their impact on repeat purchase loyalty patterns. International Journal of Research and Marketing 14(5), 473-486.

\section{Appendix}

\subsection{Remark 5}

If $F(r)=r$ then equation (6) in the main text implies that:

$$
p_{2}^{n}=\frac{1+\left(1-\bar{r}_{1}\right) 2 c}{2}
$$

Second period profits evaluated at the interior solution are given by:

$$
\pi_{2}=\frac{1}{4}\left[1-4 c^{2} \bar{r}_{1}\left(1-\bar{r}_{1}\right)\right]
$$

In the second period, if $c$ is sufficiently high, the seller may consider deviating from the interior solution, disregarding newcomers $\left(q_{2}^{n}=0\right)$ and choosing $p_{2}^{n}$ such that $p_{2}^{n}-c=p^{m}=\frac{1}{2}$. Such a deviation involves second period profits equal to:

$$
\pi_{2}=\frac{1}{4}\left(1-\bar{r}_{1}\right)
$$

Thus, the seller will choose the interior solution if and only if (11) is higher than (12), which can be written as:

$$
4 c^{2}\left(1-\bar{r}_{1}\right) \leq 1
$$

Suppose that constraint (13) is not binding. Then the first period optimization problem consists of choosing $\left(p_{1}, c\right)$ in order to maximize the present value of profits:

$$
\Pi=\left(1-\bar{r}_{1}\right) p_{1}+\frac{\delta}{4}\left[1-4 c^{2} \bar{r}_{1}\left(1-\bar{r}_{1}\right)\right]
$$

subject to: 


$$
\bar{r}_{1}=p_{1}-\frac{\delta c}{2}\left[1-c\left(1-2 \bar{r}_{1}\right)\right]
$$

From the first order conditions we obtain that $c=\frac{1}{2}$ and $\bar{r}_{1}=\frac{8-\delta}{16}$. Note that constraint (13) is satisfied. If the monopolists follows such a policy then it makes $\Pi=\frac{64+80 \delta+\delta^{2}}{256}$. Alternatively, if the monopolist sets an arbitrarily high $c$, which implies that in the second period $q_{2}^{n}=0$ and $p_{2}^{n}-c=\frac{1}{2}$, then it also sets $p_{1}=\frac{1}{2}-\frac{\delta}{16}\left(\bar{r}_{1}=\frac{1}{2}-\frac{3 \delta}{16}\right)$, which implies that $\Pi=\frac{8+3 \delta}{32}<\frac{64+80 \delta+\delta^{2}}{256}$. Hence, $c=\frac{1}{2}$ and $\bar{r}_{1}=\frac{8-\delta}{16}$ is the monopolist's optimal discount policy.

From equation (5) in the main text:

$$
\Delta W=\delta\left(1-\bar{r}_{1}\right) \int_{\frac{1-\bar{r}_{1}}{2}}^{\frac{1}{2}} r d r-\delta \bar{r}_{1} \int_{\frac{1}{2}}^{1-\frac{\bar{r}_{1}}{2}} r d r+\int_{\bar{r}_{1}}^{\frac{1}{2}} r d r
$$
0 .

Evaluating this expression at $\bar{r}_{1}=\frac{8-\delta}{16}$ we determine that $\Delta W=-\frac{\delta^{2}}{64}\left(1-\frac{\delta}{4}\right)<$

\subsection{Remark 7}

If the firm can commit to the price for repeat purchases, and $F(x)=x$, then it chooses $p_{2}^{r}=0$ (in the first period) and $p_{2}^{n}=\frac{1}{2}$. Therefore, second period profits are $\pi_{2}=\frac{\bar{r}_{1}}{4}$. The firm chooses in the first period a price $p_{1}$ in order to maximize:

$$
\Pi=\left(1-\bar{r}_{1}\right) p_{1}+\frac{\delta}{4} \bar{r}_{1}
$$

subject to $\bar{r}_{1}=p_{1}-\frac{3 \delta}{8}$. Thus, at the optimal policy $\bar{r}_{1}=\frac{8-\delta}{16}$ and $\Pi=$ $\frac{64+80 \delta+\delta^{2}}{256}$, which coincide with those results obtained in the optimal discount policy.

\subsection{Remark 8}

For simplicity, let us consider the case $\delta=1$.

EXAMPLE 1

Suppose that $r=\frac{1}{2}$, with probability $\frac{1}{2}$, and $r$ is a random draw from a uniform distribution on $[0,1]$, with the complementary probability. Then the static monopoly price is $p^{m}=\frac{1}{2}$, and monopoly profits per period are $\frac{3}{8}$. 
For the moment suppose that in the first period, the monopolist sets $p_{1}$ and LRs such that all consumers with $r_{1} \geq \frac{1}{2}$ purchase in the first period. Hence, total sales are $\frac{3}{4}$.

If the monopolist commits to $p_{2}^{r}=0$, then $p_{2}^{n}=\frac{1}{2}$, and second period profits are $\pi_{2}=\frac{1}{4} \frac{3}{4} \frac{1}{2}=\frac{3}{32}$.

In the first period, a consumer with $r_{i}=\frac{1}{2}$ is willing to pay a price $p_{1}=r_{i}+C S(0)-C S\left(\frac{1}{2}\right)=\frac{15}{16}$.

Therefore, the present value of profits at time 1 is $\Pi=\frac{3}{4} \frac{15}{16}+\frac{3}{32}=\frac{51}{64}$.

If the monopolists sets a discount $c \leq 1$, then in the second period it will set $p_{2}^{n}=\frac{1}{2}+c$. First of all, it cannot be optimal to set $p_{2}^{n}<\frac{1}{2}$. Second, if the firm sets $p_{2}^{n}>\frac{1}{2}$ such that $p_{2}^{n}-c<\frac{1}{2}$ then second period profits are $\pi_{2}=\frac{1}{4} \frac{1}{2}\left(1-p_{2}^{n}\right) p_{2}^{n}+\frac{3}{4}\left[\frac{1}{2}+\frac{1}{2}\left(1-p_{2}^{n}+c\right)\right]\left(p_{2}^{n}-c\right)$. In this case, the optimal price is $p_{2}^{n}=\frac{7+6 c}{8}$, which implies that $p_{2}^{n}-c>\frac{1}{2}$. We have reached a contradiction. Third, if the firm sets $p_{2}^{n}$ such that $p_{2}^{n}-c \geq \frac{1}{2}$, then it finds it optimal to set $p_{2}^{n}=\frac{1}{2}+c$, which implies that second period profits are $\pi_{2}=\frac{5-2 c^{2}}{16}$.

In the first period, a consumer with $r_{i}=\frac{1}{2}$ is willing to pay a price $p_{1}=r_{i}+C S\left(\frac{1}{2}\right)-C S\left(\frac{1}{1}+c\right)=\frac{2+c-c^{2}}{4}$. Hence, the present value of profits is $\Pi=\frac{3}{4} \frac{2+c-c^{2}}{4}+\frac{5-2 c^{2}}{16}$. Thus, the optimal discount is $c=\frac{3}{10}$, which implies that the maximum amount of profits that can be obtained using a discount policy is lower than what might be obtained under a price commitment policy. ${ }^{14}$

EXAMPLE 2

Suppose that $f(r)=2$ if $r \in\left[\frac{1}{2}, 1\right]$, and $f(r)=0$, otherwise. In this case, $p^{m}=\frac{1}{2}$ and profits per period are also $\frac{1}{2}$ (present value of profits is equal to 1 ). It is noteworthy that under such a policy total welfare is maximized.

Clearly, monopolists cannot benefit from a price commitment policy, since there are not further gains from trade. However, a discount policy can increase profits with respect to the no commitment case. In particular, consider $p_{1}=1, c=\frac{1}{2}$. In the first period consumers will anticipate that $p_{2}^{n}=1$, and hence all consumers with $r_{i} \geq \frac{1}{2}$ will be willing to buy the good in the first period. As a result the present value of profits is $\Pi=\frac{5}{4}>1$.

\footnotetext{
${ }^{14}$ It can easily be checked that the monopolist cannot do better by setting $p_{1}$ such that $\bar{r}_{1} \neq \frac{1}{2}$.
} 


\subsection{Lemma 9}

Let us first consider case $(\mathrm{i}) \bar{r}_{1} \leq p_{2}^{r} \leq p_{2}^{n}$. In this case, the firm's present value of profits in the first period is:

$$
\begin{gathered}
\Pi_{1}\left(p_{1}, p_{2}^{r}, p_{2}^{n}\right)=\left[1-F\left(\bar{r}_{1}\right)\right] p_{1}+\delta\left\{\left[1-\epsilon F\left(\bar{r}_{1}\right)\right]\left[1-F\left(p_{2}^{r}\right)\right] p_{2}^{r}+\epsilon F\left(\bar{r}_{1}\right) \pi\left(p_{2}^{n}\right)\right\} \\
\bar{r}_{1}=p_{1}+\delta \epsilon\left[C S\left(p_{2}^{n}\right)-C S\left(p_{2}^{r}\right)\right]
\end{gathered}
$$

From the first order conditions of the firm's optimization problem, we can characterize as follows the candidate to the monopoly solution:

$$
\begin{gathered}
1-F\left(p_{2}^{n}\right)-F\left(\bar{r}_{1}\right) f\left(p_{2}^{n}\right) p_{2}^{n}=0 \\
1-F\left(p_{2}^{r}\right)-\frac{1-\varepsilon F\left(\bar{r}_{1}\right)}{1-\epsilon} f\left(p_{2}^{r}\right) p_{2}^{r}=0 \\
1-F\left(\bar{r}_{1}\right)-\bar{r}_{1} f\left(\bar{r}_{1}\right)-f\left(\bar{r}_{1}\right) \delta \epsilon\left[T S\left(p_{2}^{r}\right)-T S\left(p_{2}^{n}\right)\right]=0
\end{gathered}
$$

Note that as $\epsilon$ goes to zero, both $p_{2}^{r}$ and $\bar{r}_{1}$ go to $p^{m}$. Consider the following deviation: $p_{2}^{r}=0$ and $p_{1}$ such that $\bar{r}_{1}$ and $p_{2}^{n}$ remain unchanged. The firm can charge a higher $p_{1}$ and the difference is equal to $\delta(1-\epsilon) \bar{r}_{1}+$ $\delta \epsilon\left[C S(0)-C S\left(p_{2}^{r}\right)\right]$, where $\bar{r}_{1}$ and $p_{2}^{r}$ are the candidate of the monopoly solution. Thus, the change in profits associated with the deviation can be written as a function of $\epsilon$ :

$$
\Delta \Pi^{d}(\epsilon)=\delta(1-\epsilon)\left[\pi\left(\bar{r}_{1}\right)-\pi\left(p_{2}^{r}\right)\right]+\delta \epsilon\left[1-F\left(\bar{r}_{1}\right)\right]\left[T S(0)-T S\left(p_{2}^{r}\right)\right]
$$

Note that $\Delta \Pi^{d}(0)=0$, since at $\epsilon=0 p_{2}^{r}=\bar{r}_{1}=p^{m}$. Also,

$$
\frac{d \Delta \Pi^{d}(\epsilon)}{d \epsilon}=\delta\left(\Omega_{1}+\Omega_{2}+\Omega_{3}+\Omega_{4}\right)
$$

where

$$
\begin{gathered}
\Omega_{1}=-\left[\pi\left(\bar{r}_{1}\right)-\pi\left(p_{2}^{r}\right)\right] \\
\Omega_{2}=\left[1-F\left(\bar{r}_{1}\right)\right]\left[T S(0)-T S\left(p_{2}^{r}\right)\right]
\end{gathered}
$$




$$
\begin{gathered}
\Omega_{3}=\left\{-\epsilon f\left(\bar{r}_{1}\right)\left[T S(0)-T S\left(p_{2}^{r}\right)\right]+(1-\epsilon) \pi^{\prime}\left(\bar{r}_{1}\right)\right\} \frac{d \bar{r}_{1}}{d \epsilon} \\
\Omega_{4}=\left\{-(1-\epsilon) \pi^{\prime}\left(p_{2}^{r}\right)-\epsilon\left[1-F\left(\bar{r}_{1}\right)\right] f\left(p_{2}^{r}\right) p_{2}^{r}\right\} \frac{d p_{2}^{r}}{d \epsilon}
\end{gathered}
$$

Note that evaluated at $\epsilon=0, \Omega_{1}=\Omega_{3}=\Omega_{4}=0$ and $\Omega_{2}>0$. Hence, $\frac{d \Delta \Pi^{d}(\epsilon=0)}{d \epsilon}>0$. Therefore, provided $\epsilon$ is a strictly positive, arbitrarily small number, such a deviation is profitable and hence we can rule out case (i).

Ruling out a solution of type (iii) is much simpler. Suppose we have a solution such that $p_{2}^{r} \leq p_{2}^{n}<\bar{r}_{1}$. In this case:

$$
\bar{r}_{1}=p_{1}+\delta\left[(1-\epsilon)\left(p_{2}^{r}-p_{2}^{n}\right)+\epsilon C S\left(p_{r}^{n}\right)-C S\left(p_{2}^{r}\right)\right]
$$

The firm's profits in period 1 are:

$\Pi_{1}=\left[1-F\left(\bar{r}_{1}\right)\right] p_{1}+\delta\left\{\left[1-F\left(\bar{r}_{1}\right)\right]\left[1-\epsilon F\left(p_{2}^{r}\right)\right] p_{2}^{r}\right\}+\left\{F\left(\bar{r}_{1}\right)-\left[1+\epsilon+\epsilon F\left(p_{2}^{n}\right)\right] p_{2}^{n}\right\}$

The first order condition with respect to $p_{2}^{n}$ evaluated at $p_{2}^{n}=p^{m}$ is:

$$
\frac{\partial \Pi_{1}}{\partial p_{2}^{n}}\left(p_{2}^{n}=p^{m}\right)=\delta(1-\epsilon)\left[1-F\left(\bar{r}_{1}\right)\right]\left[1-F\left(p^{m}\right)\right]>0
$$

This inequality together with the second order condition implies that $p_{2}^{n}>p^{m}$. However, the first order condition with respect to $\bar{r}_{1}$ implies that $\bar{r}_{1}<p^{m}$. We have reached a contradiction.

\subsection{Lemma 12}

Let us first consider case (ii) $p_{2}^{n}-c<\bar{r}_{1}$. Then in the second period the firm chooses $p_{2}^{n}$ in order to maximize:

$$
\Pi_{2}=\left[1-F\left(\bar{r}_{1}\right)\right]\left[1-\epsilon F\left(p_{2}^{n}-c\right)\right]\left(p_{2}^{n}-c\right)+\epsilon F\left(\bar{r}_{1}\right) \pi\left(p_{2}^{n}\right)
$$

In this case, provided $\epsilon$ is sufficiently small, $\frac{d \Pi_{2}}{d p_{2}^{n}}>0$.

Next, suppose the solution satisfies (iii) $p_{2}^{n}<\bar{r}_{1}$. Then in the second period the firm chooses $p_{2}^{n}$ in order to maximize:

$$
\Pi_{2}=\left[1-F\left(\bar{r}_{1}\right)\right]\left[1-\epsilon F\left(p_{2}^{n}-c\right)\right]\left(p_{2}^{n}-c\right)+
$$




$$
+\left\{F\left(\bar{r}_{1}\right)-\left[1-\epsilon+\epsilon F\left(\bar{r}_{1}\right)\right] F\left(p_{2}^{n}\right)\right\} p_{2}^{n}
$$

It turns out that:

$\frac{d \Pi_{2}}{d p_{2}^{n}}\left(p_{2}^{n}=p^{m}\right)=\epsilon\left[1-F\left(\bar{r}_{1}\right)\right]\left[1-F\left(p_{2}^{n}-c\right)-f\left(p_{2}^{n}-c\right)\left(p_{2}^{n}-c\right)\right]>0$

Hence, $p_{2}^{n}>p^{m}>\bar{r}_{1}$. We have reached a contradiction. 